\title{
Perioperative Management of Patients with Inflammatory Rheumatic Diseases Undergoing Major Orthopaedic Surgery: A Practical Overview
}

\author{
Roberta Gualtierotti (D) Marco Parisi · Francesca Ingegnoli
}

Received: February 5, 2018 / Published online: March 20, 2018

(c) The Authors 2018

\begin{abstract}
Patients with inflammatory rheumatic diseases often need orthopaedic surgery due to joint involvement. Total hip replacement and total knee replacement are frequent surgical procedures in these patients. Due to the complexity of the inflammatory rheumatic diseases, the perioperative management of these patients must envisage a multidisciplinary approach. The frequent association with extraarticular comorbidities must be considered when evaluating perioperative risk of the patient and should guide the clinician in the decisionmaking process. However, guidelines of different medical societies may vary and are
\end{abstract}

Enhanced content To view enhanced content for this article go to https://doi.org/10.6084/m9.figshare. 5929225 .

R. Gualtierotti

Lupus Clinic, Department of Rheumatology and

Medical Sciences, ASST Pini-CTO, Milan, Italy

R. Gualtierotti $(\bowtie) \cdot$ F. Ingegnoli

Department of Clinical Sciences and Community

Health, University of Milan, Milan, Italy

e-mail: roberta.gualtierotti@unimi.it

M. Parisi

Department of Orthopaedic Surgery and

Traumatology, San Paolo Hospital, ASST Santi Paolo

e Carlo, Milan, Italy sometimes contradictory. Orthopaedics should collaborate with rheumatologists, anaesthesiologists and, when needed, cardiologists and haematologists with the common aim of minimising perioperative risk in patients with inflammatory rheumatic diseases. The aim of this review is to provide the reader with simple practical recommendations regarding perioperative management of drugs such as diseasemodifying anti-rheumatic drugs, corticosteroids, non-steroidal anti-inflammatory drugs and tools for a risk stratification for cardiovascular and thromboembolic risk based on current evidence for patients with inflammatory rheumatic diseases.

Keywords: Biological; DMARD; Inflammatory rheumatic diseases; Perioperative management; Rheumatoid arthritis; Systemic lupus erythematosus

\section{INTRODUCTION}

Inflammatory rheumatic diseases (IRD) are chronic systemic autoimmune diseases. Considering that the prevalence of rheumatoid arthritis (RA) is $0.5-1 \%$, of psoriatic arthritis (PsA) is around $0.16 \%$ and of systemic lupus erythematosus (SLE) is up to $0.1 \%$ of the general population, overall they are frequent diseases [1]. Due to the association with multiple 
comorbidities, IRD need a multidisciplinary management. Compared with healthy subjects, patients with IRD are also burdened with a higher risk of infections, due to the immunosuppressive treatment with disease-modifying anti-rheumatic drugs (DMARDs) and corticosteroids, an increased cardiovascular (CV) risk, and a major risk of an altered coagulation state, in turn due both to inflammation and, in some cases, to the presence of anti-phospholipid antibodies (aPL) [2-6].

Patients with IRD may need to undergo joint replacement to restore function when joints have been severely damaged by complications related to their underlying disease, such as inflammatory arthritis, osteonecrosis or secondary osteoarthritis; however, due to the improved medical management and better health conditions in recent decades, rates of orthopaedic surgery for age-related osteoarthritis are increasing [7]. Da Silva et al. documented a $34 \%$ estimated cumulative incidence of joint surgery at 30 years in a longitudinal study conducted from 1955 to 1995 in RA patients [8]. The same authors have reported an overall trend towards a reduction in joint surgery in those patients who were diagnosed as having RA after 1985. Later studies have confirmed that the incidence of total hip arthroplasty (THA) and total knee arthroplasty (TKA) in RA patients has decreased in the last decades, probably due to an earlier diagnosis, a prompt treatment initiation, and the introduction of biological drugs in the treatment armamentarium $[9,10]$. Other studies have shown that $4 \%$ of SLE patients and $7 \%$ of a PsA cohort undergo arthroplasty $[11,12]$. The majority of patients with SLE undergoing THA or TKA are on immunosuppressive medications at the time of surgery [13]. Nevertheless, the perioperative management of patients with IRD is still not standardised.

Against this background, perioperative care of patients with IRD requires standardisation and a multidisciplinary approach envisaging a collaboration between rheumatologists and orthopaedics, with the aim of performing an appropriate risk assessment and minimizing perioperative risk.

\section{METHODS}

In this narrative review, we analysed recent evidence regarding the perioperative management of patients with IRD undergoing major orthopaedic surgery. We searched PubMed with no temporal limitations and performed a critical analysis of the most recent literature published in English, focusing on the last 5 years.

\section{Compliance with Ethics Guidelines}

This article is based on previously conducted studies and does not contain any studies with human participants or animals performed by any of the authors.

\section{Disease-Modifying Anti-rheumatic Drugs (DMARDs)}

As far as immunosuppressive treatment is concerned, a careful risk-benefit analysis should be performed in each patient. On the one hand, clinicians should be aware of risk factors associated with surgical site infection and woundhealing complications, such as age, comorbidities, type and site of surgery, history of previous infection, disease activity and immunosuppressive treatment $[2,14]$. On the other hand, discontinuation of DMARDs can result in disease flares, and evidence supports the view that continuing with DMARDs is a safe option in RA patients without relevant comorbidities [15]. In this setting, the American College of Rheumatology (ACR), in agreement with the American Association of Hip and Knee Surgeons (AAHKS), recently proposed guidelines for the perioperative management of DMARDs in IRD patients undergoing elective THA or TKA [16]. The guidelines separately address patients with severe and non-severe manifestations of SLE in optimal conditions for surgery (Fig. 1).

The first ACR/AAHKS recommendation suggests continuing the current dose of methotrexate (MTX), leflunomide (LEF), hydroxychloroquine, and/or sulfasalazine in patients with RA, spondyloarthritis (SpA) including ankylosis spondylitis (AS) and PsA 


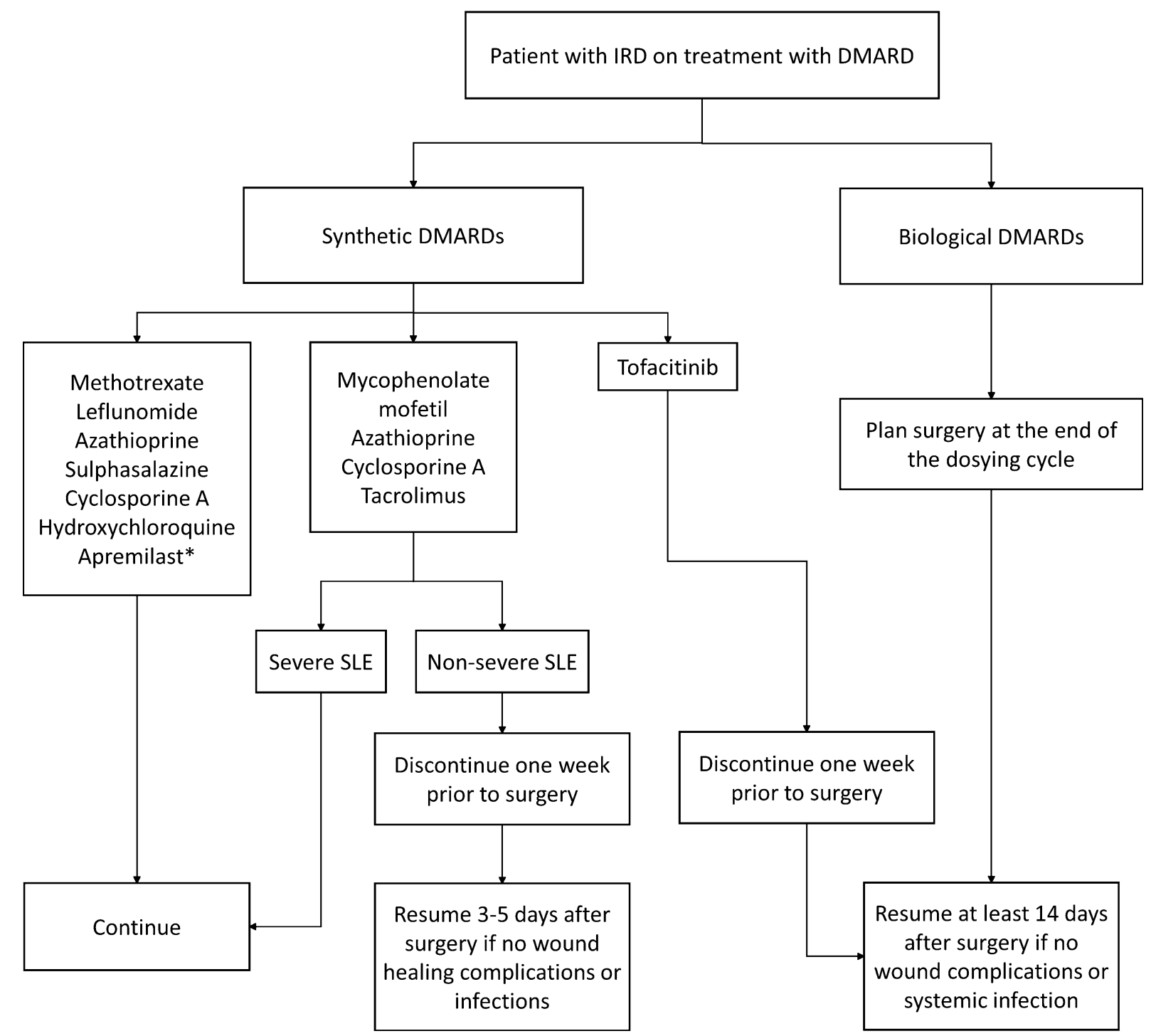

Fig. 1 Management of synthetic and biological diseasemodifying anti-rheumatic drugs in patients with inflammatory rheumatic diseases undergoing total hip or knee arthroplasty. DMARD disease-modifying anti-rheumatic

and SLE undergoing elective THA or TKA [16]. Evidence is available for RA patients, and MTX is one of the best characterised DMARDs as far as perioperative management is concerned. The largest prospective cohort study concerning the evaluation of discontinuation of MTX perioperatively in patients with RA has been presented by Grennan et al. demonstrating no increase in the rate of infections and surgical complications within 1 year of elective orthopaedic surgery if drugs, $S L E$ systemic lupus erythematosus. *No evidence, in high-risk patients suspend 3 days before surgery

MTX was continued [15]. However, perioperative risk was increased by the intercurrent presence of chronic diseases like diabetes or steroid treatment. Indeed, discontinuation of MTX in the perioperative period increases the risk of disease flares: after 6 weeks from surgery, no flares occurred in those patients who continued MTX, whereas almost $10 \%$ of those who discontinued MTX experienced a flare. Other studies confirmed the observation of a higher 
risk of disease flares in patients discontinuing MTX treatment in the perioperative period [17].

Data on other DMARDs are sparse. However, it is widely recognised that hydroxychloroquine is not a potent immunosuppressant, rather an immunomodulatory drug, and, due to its extremely favourable toxicity profile and safety in the perioperative period, can be continued $[18,19]$. Indeed, in patients with SLE, hydroxychloroquine reduces disease activity, CV risk, insulin resistance and thromboembolic events; therefore, in the perioperative period, it should not be discontinued and could even be protective [20-22].

Conflicting results have been published in regard to leflunomide (LEF) [23-25]. A significant increase in wound-healing complications has been reported in patients treated with LEF, as compared with patients treated with MTX [26]. However, no difference was found in the risk of complications between patients who continued LEF and patients in whom LEF was stopped 1 month before surgery [27]. In one prospective study, patients with RA and LEF was associated with a higher risk of postoperative wound complication [26]. It is not surprising that recommendations regarding the perioperative use of LEF differ [28]. Müller and PippiLudwig suggested continuing LEF alone for patients undergoing low-risk procedures and cotreating patients undergoing high-risk procedures with cholestyramine [29].

There is general agreement on the safety of continuing perioperatively other immunosuppressors such as azathioprine and sulfasalazine, although some authors suggest withholding of these drugs the day of surgery [30-34]. In one retrospective study, sulfasalazine was associated with a lower risk of perioperative infection [32].

JAK inhibitors have been introduced more recently in RA treatment as targeted synthetic DMARDs for JAK/STAT pathway blockade. Tofacitinib is the first inhibitor of the JAK1 and JAK3 signalling pathways that has demonstrated efficacy in controlling disease in RA [35]. Tofacitinib half-life is very short $(3-4 \mathrm{~h})$ [36]. Recommendations suggest stopping this medication 1 week prior to surgery, although evidence comes from meta-analyses in nonsurgical patients [16].
The ACR/AAHKS recommendations define severe SLE patients those currently treated with induction or maintenance therapy for severe organ manifestations such as lupus nephritis, central nervous system involvement, severe haemolytic anemia, severe thrombocytopenia, vasculitis (other than mild cutaneous vasculitis), myocarditis, lupus pneumonitis, severe myositis, lupus enteritis (vasculitis), lupus pancreatitis, cholecystitis or hepatitis, protein-losing enteropathy, malabsorption, orbital inflammation/myositis, severe keratitis, posterior severe uveitis/retinal vasculitis, severe scleritis, optic neuritis, anterior ischemic optic neuropathy [16]. The recommendation for severe SLE patients is to continue the current dose of MTX, mycophenolate mofetil, azathioprine, cyclosporine, or tacrolimus through the surgical period, due to the risk of flare outweighing the risk of severe complications. This recommendation is based on the lack of sound evidence in severe SLE patients and on the presence of indirect evidence from transplant patients continuing immunosuppressive treatment in the surgical period [37, 38]. However, the ACR/ AAHKS Panel also recognises the importance of taking decisions on an individual basis [16].

In non-severe SLE, the recommendation is to withhold the current dose of mycophenolate mofetil, azathioprine, cyclosporine or tacrolimus 1 week before the surgery, allowing a return of immune function. These medications have to be restarted 3-5 days after surgery, in the absence of wound healing and infections. This recommendation is linked to the Panel's idea that careful monitoring of the patient after surgery would permit the medications to be restarted prior to clinical flares [16].

Even if there is no evidence specifically regarding the perioperative management of cyclosporine in PsA patients, three studies regarding cyclosporine use in IBD patients found no elevated risk of complications. All the patients with individual risk factors and comorbidities have to be evaluated case-by-case $[39,40]$. Apremilast is a targeted synthetic DMARD indicated for PsA [41]. Patients undergoing major surgery within 8 weeks prior to study, and patients with a planned major surgery within 6 months following initial 
randomization, were excluded from the registrational PALACE study [42], therefore there are no current recommendations for the perioperative use of apremilast (http://www. ema.europa.eu/ema/index.jsp?curl=pages/medi cines/human/medicines/003746/human_med_ 001835.jsp\&mid=WC0b01ac058001d124). However, it is an overall safe drug, which carries a low risk of serious infections [42]. For further safety in high-risk patients, it may be stopped 3 days before surgery, based on its half-life.

\section{Biological DMARDs}

The management of biological agents in the perioperative period is a clinical dilemma, due to the need to balance infectious risk and compromised healing and the risk of disease flares. Until now, a suspension period of two half-lives of the biological drugs has been suggested. However, no randomised clinical trials are currently available for IRD patients undergoing THA or TKA. After a systematic review of the literature, the ACR/AAHKS Panel found that the risk of serious infections was increased with biological agents, with most odds/hazards/risk ratios $\sim 1.5$ (range 0.61-8.87) and a higher risk of serious adverse events with most odds/hazards/risk ratios $\sim 1.5$ (range 0.33-2.54), with no relevant differences among available biological agents [16]. Similar evidence is also available for psoriatic arthritis [43]. Therefore, the ACR/ AKHS recommendation suggests that RA, SpA and non-severe SLE patients should stop all current biological agents prior to elective THA or TKA, planning the surgery at the end of the dosing cycle for that specific medication [16].

The choice to resume these medications at minimum 14 days after surgery is based on the normal time of wound healing, but in IRD patients should be based on an individual basis, considering possible complications in wound healing and ruling out surgical site or systemic infections [16]. The recommendations also take into account biologics specifically indicated for PsA and other SpA, such as ustekinumab and secukinumab [16].

As far as B cell-targeted therapies, after a systematic review of the ACR/AAKHS in non- surgical patients with RA and SLE, a risk of serious infections with rituximab with a relative risk (RR) ranging from 0.66 to 0.73 [41, 45], and a risk for all serious adverse events with a range of RRs from 0.85 (95\% CI $0.62-1.17)$ to 0.89 (95\% CI 0.7-1.14), emerged. However, most data were indirect and the Panel considered these medications to be similar to tumor necrosis factor inhibitors used for the treatment of RA, which usually have a risk of infection [16]. Moreover, rituximab is not approved by the US Food and Drug Administration (FDA) for treatment of SLE, and belimumab, although FDA-approved for use in SLE, has not been studied in manifestations of severe SLE (e.g. lupus nephritis) [44, 45], so the Panel recommended withholding these medications prior to surgery and planning the surgery for the end of the dosing cycle, due to the risk of infection and the paucity of data supporting perioperative benefit in SLE [44, 46, 47].

\section{Non-steroidal Anti-inflammatory Drugs (NSAIDs)}

Non-steroidal anti-inflammatory drugs (NSAIDs) are used for pain and stiffness in patients with inflammatory arthritis such as RA and SLE, and are a mainstay in the treatment of SpA [48]. NSAIDs directed against cyclooxygenase (COX)1 and non-selective COX inhibitors exert their anti-inflammatory effect by reversibly blocking the enzymes of the COX family, subsequently decreasing prostaglandin synthesis, but they also exert an antiplatelet effect, implying increased risk of bleeding $[49,50]$. NSAIDs have variable half-lives ranging from 2 to $6 \mathrm{~h}$ (ibuprofen, ketoprofen, indomethacin), to 7-15 h (celecoxib, naproxen, diflunisal), to $>20 \mathrm{~h}$ (meloxicam, nabumetone, piroxicam) [52]. It is advisable to withhold NSAIDs preoperatively for a period equivalent to five half-lives of the drugs [52] and to re-start them 2-3 days postoperatively [53].

Acetilsalicilic acid/aspirin is an irreversible inhibitor of platelet function. Due to its wide use as an anti-platelet agent for primary and secondary prevention in patients with IRD, perioperative management of acetilsalicilic acid will be reviewed below. 
Selective COX-2 inhibitors, also known as coxibs, were developed to minimize NSAID-related side effects, and do not appear to significantly increase the risk of perioperative bleeding [54], but they have been suggested to increase the risk of CV events [55-58]. The use of coxibs has been discouraged in patients who have a high CV risk or who have thrombophilic factors such as patients with SLE and antiphospholipid antibodies [59]. However, in a recent study, one of the coxibs, celecoxib, was found to be non-inferior to ibuprofen or naproxen with regard to $\mathrm{CV}$ safety if given in moderate doses [60]. Evidence from animal studies suggests that COX-2 inhibitors may also have a negative effect on tendon healing and tendon to bone attachment [61]. This is probably due to the inhibition of the inflammatory response, as prostaglandins in particular facilitate the formation of bone, increasing the proliferation and differentiation of osteoblasts [62-64]. Similar evidence has also been found for non-selective NSAIDs [65]. Based on these findings, the perioperative use of NSAIDs should be carefully evaluated in patients with IRD, due to the increased CV risk, and, although data are controversial, due to the possible interference with wound healing, which in patients with IRD could be already impaired due to other treatments such as DMARDs and corticosteroids. Although coxibs are not associated with an increased postoperative bleeding risk and are considered safe perioperatively [66], they may also interfere with wound healing. The association of paracetamol with opioids in the postoperative period could be a safe and effective alternative [67].

\section{Corticosteroids}

Patients on chronic corticosteroid therapy undergoing major orthopaedic surgery are often given high perioperative doses (named "stressdose") out of fear of adrenal gland insufficiency [68]. The cut-off dose of corticosteroids able to induce immunosuppression and hypothalamic-pituitary-adrenal axis suppression has long been debated and has not been established yet $[69,70]$. There is evidence that a dose of
$20 \mathrm{mg}$ of prednisone for 5 days is already sufficient to inhibit cortisol synthesis, while the length of corticosteroid treatment is also a relevant issue [71]. However, the long-term use of corticosteroids is associated with an increased risk of perioperative infection and woundhealing complications [72-74]. RA patients taking chronic corticosteroids have increased rates of joint infections after joint replacement, with a risk 2.5-3 times greater than that of the general population [75]. Cosyntropin testing, which has been suggested in the past as a preoperative screening for adrenal insufficiency, has been demonstrated to be unreliable, because it may also result positive in those patients with secondary adrenal insufficiency which can actually increase the production of endogenous glucocorticoids [76]. For this reason, it is no longer recommended [70]. The usefulness of a preoperative corticosteroid stress-dose has long been debated. Although there is no evidence of an increased risk of adverse events in patients taking a perioperative stress-dose compared with the usual dose of corticosteroids [77], there is no proof-of-concept that a routine administration of a stressdose may reduce the risk of haemodynamic instability in adult patients with IRD undergoing major orthopaedic surgery receiving $\leq 16 \mathrm{mg}$ /day prednisone or equivalent [70, 78].

Based on this evidence, the ACR/AAKHS guidelines recommend not to routinely administer a preoperative stress-dose to patients, as long as they continue the usual daily dose of corticosteroids, which should whenever possible, be gradually tapered to a daily dose of prednisone or equivalent of $<20 \mathrm{mg}$ before surgery, [16]. Nevertheless, patients with IRD in chronic corticosteroids therapy should be carefully monitored and given additional steroid doses if they develop signs of haemodynamic instability such as hypotension or tachycardia [70, 79]. Recommendations do not refer to patients with primary adrenal insufficiency or primary hypothalamic disease, who must be managed differently [70].

In those patients who are taking a daily dose of steroids- $>15 \mathrm{mg}$ of prednisone or equivalent-who cannot reduce the dosage due to the risk of disease flare, it is especially important to ensure meticulous sterile techniques, careful 
intraoperative skin handling, tight closure and proper antibiotic prophylaxis [80]. The use of other non-pharmacological strategies such as antibiotic-loaded bone cement was proposed almost 10 years ago as an appropriate measure in high-risk patients-such as those affected by IRDs or other chronic diseases predisposing to perioperative infections-and has nowadays become a widespread measure [81].

In those patients taking high-dose steroid treatment who plan to undergo elective surgery, it is recommendable, if possible, to wait until a better control of disease activity is achieved or until the steroid dosage is reduced, if tapering is planned in the short-medium term.

\section{Perioperative Antibiotic Prophylaxis}

There is currently no evidence that patients with IRD should follow a perioperative antibiotic protocol different from the general population. Therefore, we recommend to follow the available guidelines for the prevention of surgical site infections. Current guidelines suggest the use of cefazolin-or vancomycin or clindamycin in the case of beta-lactam allergy-for total joint replacement. For procedures in which there is a risk of contamination by pathogens other than staphylococci and streptococci, an additional agent should be considered. Local and national surveillance data are pivotal in such cases [82]. The presence of MRSA contamination should be ruled out in order to plan the appropriate antibiotic treatment. It is well known that nasal carriers are likely to have extranasal contamination sites with the same strain $[83,84]$. The optimal timing and duration of prophylactic antibiotics is still controversial. Current guidelines suggest starting intravenous prophylactic antibiotics within $60 \mathrm{~min}$ before skin incision and stopping it within $24 \mathrm{~h}$ postoperatively [SIGN publication no. 104, July 2008, http://www.sign.ac.uk] [85].

\section{Management of Cardiovascular Risk and Anti-platelet Agents}

Patients with IRD have a higher risk of CV events than the general population, and this burden is not fully explained by traditional risk factors, with chronic inflammation playing a pivotal role $[4,6$, 86]. Recently, the European League against Rheumatism (EULAR) suggested recommendations for the assessment and management of CV risk in RA patients [87]. Patients with IRD may be at higher risk for CV complications when undergoing arthroplasty [88]. CV events are a major perioperative complication in orthopaedic surgery, particularly in those patients with underlying $\mathrm{CV}$ risk factors [89]. In a large cohort of patients undergoing major non-cardiac surgery, Lee et al. reported a $2.1 \%$ rate of major postoperative CV complications [90]. SLE patients are burdened by a risk of CAD 50 times higher than age-matched controls, but studies regarding perioperative $\mathrm{CV}$ risk are few and controversial [91]; however, postarthroplasty mortality seems to be increased, in particular after non-elective arthroplasty [92].

Before surgery, the American College of Cardiology/American Heart Association (ACC/ AHA) [93] recommends the stratification of CV risk by means of instruments such as the American College of Surgeons National Surgical Quality Improvement Program (NSQIP). Five predictors of perioperative myocardial infarction/cardiac arrest are included: type of surgery, functional status, elevated creatinine $(>1.5 \mathrm{mg} /$ dL), American Society of Anesthesiologists (ASA) class (Class I, patient completely healthy; Class II, patient with mild systemic disease; Class III, patient with severe systemic disease that is not incapacitating; Class IV, patient with incapacitating disease that is a constant threat to life; and Class V, a moribund patient who is not expected to live for $24 \mathrm{~h}$, with or without the surgery), and age (http://www.sur gicalriskcalculator.com/miorcardiacarrest) [94]. This tool does not take into account other factors specifically related to the presence of an IRD or of specific disease-related CV risk factors such as the presence of antiphospholipid antibodies, which should instead be considered during CV risk stratification [95].

Concerns over promoting perioperative bleeding often lead surgeons to discontinue aspirin in the perioperative period. Aspirin is an irreversible inhibitor of the constitutive isoform of the platelet enzyme (COX-1) on which it is 
$>100$ times more potent than on the inducible isoform (COX-2) which is expressed after activation by cytokines, inflammatory stimuli, and some growth factors. This explains the different dosage requirements of aspirin as an antithrombotic, acting on COX-1, and an antiinflammatory drug, acting on COX-2, respectively [96]. However, in a large retrospective study, Smilowitz et al. confirmed that perioperative aspirin was not associated with a higher risk of bleeding if given in selected cases [97]. Initiation of aspirin before elective noncardiac, noncarotid surgery as primary prevention is not supported by evidence, as it may imply a higher bleeding risk and therefore should not be routinely performed [93]. The American College of Chest Physicians (ACCP) recommend that, for patients at moderate to high risk for $\mathrm{CV}$ events who are receiving ASA therapy as a secondary prevention, ASA should be continued around the time of surgery instead of stopping it [98-100]. Such moderate- to high-risk patients include those with ischemic heart disease, congestive heart failure, diabetes mellitus, renal insufficiency, or cerebrovascular disease according to the ACCP guidelines [101]. However, IRD is per se a CV risk factor that should be added to the list of $\mathrm{CV}$ risk factors, and patients with aPL antibodies, especially with triple positivity of laboratory tests, should be considered at high risk of a first thrombotic event [87]. Therefore, considering the low risk of lifethreatening bleeding with aspirin, if no major contraindications are present, the continuation of aspirin is feasible and recommended in all IRD patients who are already in treatment (Fig. 2) [101].

The 2014 ACC/AHA Guideline on Perioperative Cardiovascular Evaluation and Management of Patients Undergoing Noncardiac Surgery suggest that revascularization before noncardiac surgery is recommended only when indicated by existing clinical practice guidelines [93]. To avoid stent re-thrombosis, elective orthopaedic surgery should be delayed after percutaneous intervention for 14 days after balloon angioplasty and for 30 days after baremetal stent implantation, whereas it should be avoided for at least 365 days after drug-eluting stent implantation. In patients who have received coronary stents and are undergoing double antiplatelet therapy, it is recommended that aspirin be continued if possible and that the P2Y12 platelet receptor-inhibitor should be restarted as soon as possible after surgery (Fig. 2).

Beta-blockers should be continued in patients who are treated chronically [93]. Initiation of hydroxychloroquine for a CV protective effect [22], of a beta-blocker for heart rate control, of statins for endothelial and CV risk reduction may provide additional protection with very low risk of side effects, and may be considered in some patients [93].

\section{Management of Venous Thromboembolism (VTE) and Anti- coagulants}

Patients with IRD are at higher risk of venous thromboembolism (VTE), particularly after hospitalisation [102-104], but also as a consequence of chronic inflammation, which is known to induce endothelial activation [105-107], increased tissue factor expression and inhibition of endogenous anticoagulants and fibrinolysis [108]. Major orthopaedic surgery enhances the risk of VTE, not only because of the activation of the coagulation system due to tissue, bone, and venous injuries, reduced venous emptying intra- or post-surgery, and post-operative immobilisation $[109,110]$, but also due to its complexity and duration [111]. Pulmonary embolism is a largely underestimated cause of death [112].

Altered coagulation in patients with IRD may also be due to the presence of aPL antibodies, which cause an acquired thrombophilic state [113]. APS can manifest as venous or arterial thromboembolism and obstetric complications and its classification criteria require at least one clinical criteria among arterial, venous or obstetric events and one laboratory criteria among confirmed persistent positivity of lupus anticoagulant (LA), anti-cardiolipin and/or anti- $\beta 2$ glycoprotein I antibodies [114]. Patients with APS have a high risk of venous thrombosis after surgery [115], in agreement with the "second hit" theory: in addition to the 


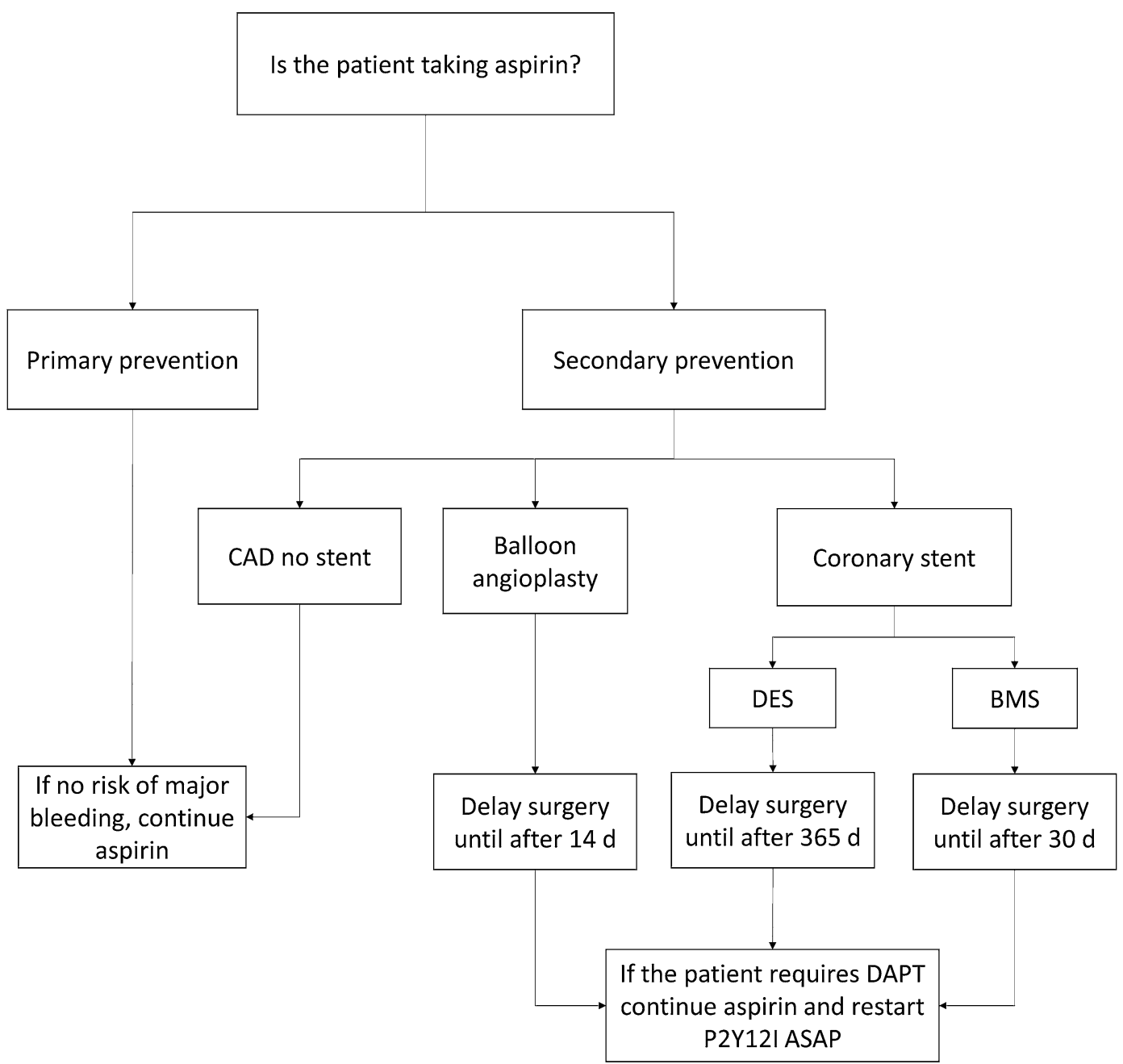

Fig. 2 Management of antiplatelet agents in patients with inflammatory rheumatic diseases undergoing total hip or knee arthroplasty. $A S A P$ as soon as possible, $B M S$ bare

presence of aPL, a second factor such as infection or surgical stress is usually needed to trigger a thromboembolic event [116].

ACR/AAHKS guidelines for arthroplasty do not treat VTE risk and, in the absence of trials specifically addressing perioperative management of anticoagulation, they recommend following the ACCP evidence-based guidelines [101]. However, these guidelines are not specifically designed to address the perioperative management of antithrombotic therapy in IRD patients. VTE risk stratification of patients with IRD should be based on previous events, metal stent, $C A D$ coronary artery disease, $D A P T$ double anti-platelet therapy, DES drug-eluted stent, P2Y12I platelet P2Y12 receptor inhibitor

aPL profile and the balancing of pro-thrombotic and bleeding risk (Fig. 3) [117]. For primary prevention in IRD patients, the perioperative risk stratification should be based on the aPL profile and other CV risk factors, considering that the presence of an IRD increases VTE risk per se [118]. The strongest predictors of clinical events in APS are LA, which raises the risk of thrombosis by approximately 4-fold [119], and triple positivity, that is positivity in all three aPL tests (LA, anticardiolipin and anti- $\beta 2$ glycoprotein antibodies), with IgG isotype clinically more meaningful compared to IgM (Fig. 3) 


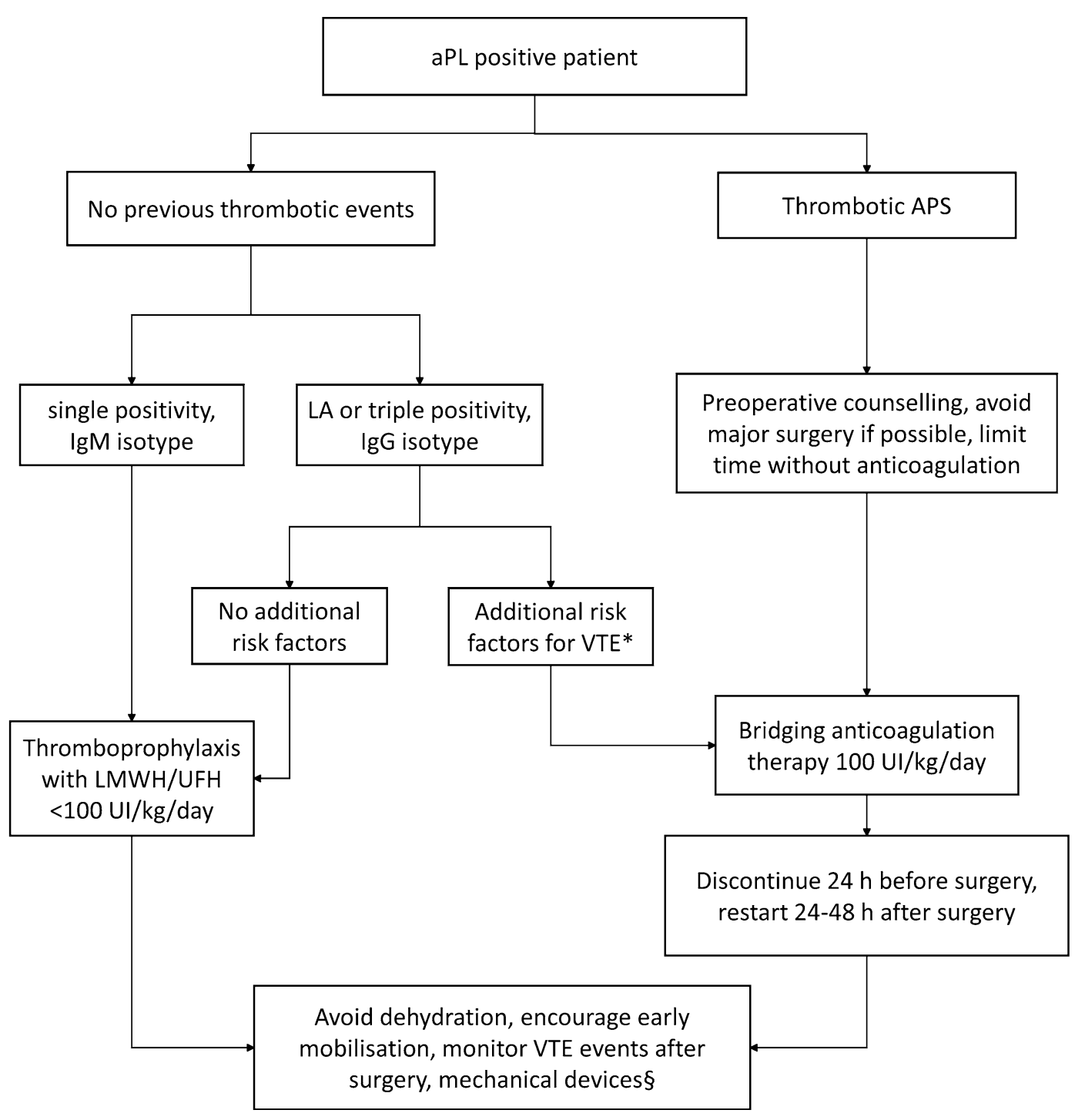

Fig. 3 Perioperative approach to the patient with inflammatory rheumatic disease and venous thromboembolic risk undergoing total hip or knee arthroplasty. aPL antiphospholipid, $L A$ lupus anticoagulant, APS anti-phospholipid syndrome, $V T E$ venous thromboembolism, $L M W H$ low molecular weight heparin, UFH unfractionated heparin. *Additional risk factors for VTE: arterial hypertension, obesity, diabetes mellitus, smoking, neoplasia, oral contraceptives, underlying inflammatory joint disease, genetic hypercoagulable state; $\$$ avoid anti-embolism

[120]. The risk assessment should also consider other CV risk factors, such as arterial hypertension, obesity (body mass index $>30 \mathrm{~kg} / \mathrm{m}^{2}$ ), diabetes mellitus, smoking, active or treated cancer, use of oral contraceptives, underlying systemic autoimmune diseases and genetic stockings in suspected or proven peripheral arterial disease, peripheral arterial bypass grafting, peripheral neuropathy or other causes of sensory impairment, any local conditions in which stockings may cause damage, for example fragile 'tissue paper' skin, dermatitis, gangrene or recent skin graft, use caution and clinical judgement when applying antiembolism stockings over venous ulcers or wounds. https:// www.nice.org.uk/guidance/cg92/chapter/1-Recommenda tions\# using-vte-prophylaxis

hypercoagulable states, which may prompt a higher dose of anti-coagulant in the perioperative time [121].

For the secondary prevention of VTE in IRD patients, due to the risk of recurrency after the first episode of thrombosis, patients with APS 
are treated with long-term oral anticoagulation and therefore require bridging with subcutaneous low-molecular-weight heparin (LMWH) or intravenous unfractionated heparin. Communication between the medical, surgical, and anaesthesiology teams is essential for a successful outcome. For patients undergoing major orthopaedic surgery, the ACCP suggests extending thromboprophylaxis in the outpatient period for up to 35 days from the day of surgery rather than for only 10-14 days, adding an intermittent pneumatic compression device (IPCD) during the hospital stay, if indicated. In patients with IRD and a full-blown APS, given the very high thrombotic risk, elective surgery should be strongly discouraged whenever possible and the least invasive option should be pursued. Appropriate bridging envisages: suspension of oral anticoagulation 3-5 days before surgery; bridging therapy with full anticoagulation with heparin or LMWH, which must be discontinued 4 or $24 \mathrm{~h}$ before surgery, respectively, and restart of full anticoagulation 24-48 $\mathrm{h}$ after the procedure if haemostasis is not compromised (Fig. 3). Despite the proper use of bridging therapy, some patients may develop thrombotic complications, particularly those with concomitant SLE [122]. Until a few years ago, vitamin $\mathrm{K}$ antagonists were the outpatient anticoagulants of choice, but many newer anticoagulants are now available [123]. Bridging guidelines should be adjusted on the basis of the washout periods of these medications as, to date, there are no consensus recommendations.

Hydroxychloroquine has been demonstrated to reduce VTE risk in SLE [124-126], and to have a CV protective effect [22]. Evidence is controversial for an additional protective effect from VTE in the perioperative period [127-131] and for primary prevention of thrombotic events in APS [132]. However, due to its excellent safety profile, this may be a safe and appropriate addition to current therapy in high-risk patients.

Other practical management strategies for potential perioperative complications should also be discussed, such as avoiding dehydration of the patient, minimising periods without anticoagulation, restarting postoperative anticoagulation as early as possible, and encouraging postoperative ambulation and mobilization as early and as much as tolerated, through the use of anti-thrombotic stockings and IPCD [117]. However, the use of anti-embolism stockings should be avoided in patients with arterial vasculopathy, leg ulcers and peripheral neuropathy, which are all frequent comorbidities in IRD patients [National Institute for Health and Clinical Excellence (NICE) (2010) CG92: Venous thromboembolism in adults admitted to hospital: reducing the risk, http://www.guidance.nice.org.uk/CG92/ Guidance].

Bleeding risks factors are previous haemorrhagic events, thrombocytopenia, use of NSAIDs and congenital or acquired haemorrhagic syndromes. Bleeding complications can occur as a result of anticoagulation therapy, thrombocytopenia or, rarely, due to Lupus anticoagulant-hypoprothrombinemia syndrome [133, 134].

Catastrophic APS (CAPS) is a rare life-threatening syndrome of unknown aetiology characterised by a rapid-onset thrombotic microangiopathy involving at least three organs associated with the confirmed presence of aPL [135]. Although it is not possible to predict the risk of this rare event, the most common precipitating factors are infections, surgery, withdrawal or improper use of anticoagulants, obstetric complications, neoplasia and disease flares in the case of concomitant SLE [136]. All of these precipitating factors, together with the pathogenic effect of aPL, in particular anti$\beta 2$ glycoprotein, may induce a generalised inflammatory response, characterised by the massive activation of a cytokine network with consequent endothelial cell activation and uncontrolled coagulation [136]. The treatment of CAPS is not standardised, due to the rarity of the disease and the consequent lack of sound evidence. Current practice is based on literature reports suggesting that prompt administration of anticoagulants, corticosteroids, plasma exchange and intravenous immunoglobulins can prolong survival in these patients $[136,137]$. Recent evidence suggests that other agents such as rituximab and eculizumab, although considered second-line treatments, could also be effective [138, 139]. 


\section{CONCLUSIONS}

The perioperative management of patients with IRD undergoing major orthopaedic surgery is challenging due to the limited available data on which to base recommendations. These patients are at high risk of infection, thrombosis and disease flare around the time of surgery, so it is essential that medical and surgical teams devise a plan to minimise patient risk. Hence, it is crucial that a multidisciplinary approach envisages orthopaedics, rheumatologists and anesthesiologists to provide a preoperative counselling with appropriate risk assessment, a close perioperative observation and a post-operative prevention plan in order to minimise perioperative risk in this group of patients. We hope this review provides a basis that enables physicians to risk stratify patients, provide personalised strategies, and address perioperative complications.

\section{ACKNOWLEDGEMENTS}

Funding. No funding or sponsorship was received for this study or publication of this article.

Authorship. All named authors meet the International Committee of Medical Journal Editors (ICMJE) criteria for authorship for this article, take responsibility for the integrity of the work as a whole, and have given their approval for this version to be published.

Disclosures. Roberta Gualtierotti, Marco Parisi and Francesca Ingegnoli have nothing to disclose.

Compliance with ethics guidelines. This article is based on previously conducted studies and does not contain any studies with human participants or animals performed by any of the authors.

Open Access. This article is distributed under the terms of the Creative Commons Attribution-NonCommercial 4.0 International
License (http://creativecommons.org/licenses/ by-nc/4.0/), which permits any noncommercial use, distribution, and reproduction in any medium, provided you give appropriate credit to the original author(s) and the source, provide a link to the Creative Commons license, and indicate if changes were made.

\section{REFERENCES}

1. Gabriel SE, Michaud K. Epidemiological studies in incidence, prevalence, mortality, and comorbidity of the rheumatic diseases. Arthritis Res Ther. 2009;11(3):229.

2. Doran MF, Crowson CS, Pond GR, O'Fallon WM, Gabriel SE. Predictors of infection in rheumatoid arthritis. Arthritis Rheum. 2002;46(9):2294-300.

3. Au K, Reed G, Curtis JR, Kremer JM, Greenberg JD, Strand $\mathrm{V}$, et al. High disease activity is associated with an increased risk of infection in patients with rheumatoid arthritis. Ann Rheum Dis. 2011;70(5):785-91.

4. Gualtierotti R. Understanding cardiovascular risk in rheumatoid arthritis: still a long way to go. Atherosclerosis. 2017;256:123-4.

5. Ward MM. Premature morbidity from cardiovascular and cerebrovascular diseases in women with systemic lupus erythematosus. Arthritis Rheum. 1999;42(2):338-46

6. Ingegnoli F, Gualtierotti R, Artusi C, Lubrano E. Focus on the potential effects of treatments for spondylarthritides on cardiovascular risk. Expert Rev Clin Immunol. 2014;10(2):307-15.

7. Mertelsmann-Voss C, Lyman S, Pan TJ, Goodman S, Figgie MP, Mandl LA. Arthroplasty rates are increased among US patients with systemic lupus erythematosus: 1991-2005. J Rheumatol. 2014;41(5):867-74.

8. da Silva E, Doran MF, Crowson CS, O'Fallon WM, Matteson EL. Declining use of orthopedic surgery in patients with rheumatoid arthritis? Results of a long-term, population-based assessment. Arthritis Rheum. 2003;49(2):216-20.

9. Weiss RJ, Stark A, Wick MC, Ehlin A, Palmblad K, Wretenberg P. Orthopaedic surgery of the lower limbs in 49,802 rheumatoid arthritis patients: results from the Swedish National Inpatient Registry during 1987 to 2001. Ann Rheum Dis. 2006;65(3):335-41. 
10. Nystad TW, Fenstad AM, Furnes O, Havelin LI, Skredderstuen AK, Fevang BT. Reduction in orthopaedic surgery in patients with rheumatoid arthritis: a Norwegian register-based study. Scand J Rheumatol. 2016;45(1):1-7.

11. Mourao AF, Amaral M, Caetano-Lopes J, Isenberg D. An analysis of joint replacement in patients with systemic lupus erythematosus. Lupus. 2009;18(14):1298-302.

12. Zangger P, Esufali ZH, Gladman DD, Bogoch ER. Type and outcome of reconstructive surgery for different patterns of psoriatic arthritis. J Rheumatol. 2000;27(4):967-74.

13. Shah UH, Mandl LA, Mertelsmann-Voss C, Lee YY, Alexiades MM, Figgie MP, et al. Systemic lupus erythematosus is not a risk factor for poor outcomes after total hip and total knee arthroplasty. Lupus. 2015;24(9):900-8.

14. Scherrer CB, Mannion AF, Kyburz D, Vogt M, Kramers-de Quervain IA. Infection risk after orthopedic surgery in patients with inflammatory rheumatic diseases treated with immunosuppressive drugs. Arthritis Care Res (Hoboken). 2013;65(12):2032-40.

15. Grennan DM, Gray J, Loudon J, Fear S. Methotrexate and early postoperative complications in patients with rheumatoid arthritis undergoing elective orthopaedic surgery. Ann Rheum Dis. 2001;60(3):214-7.

16. Goodman SM, Springer B, Guyatt G, Abdel MP, Dasa V, George M, et al. 2017 American college of Rheumatology/American association of hip and knee surgeons guideline for the perioperative management of antirheumatic medication in patients with rheumatic diseases undergoing elective total hip or total knee arthroplasty. Arthritis Care Res (Hoboken). 2017;69(8):1111-24.

17. Murata K, Yasuda T, Ito H, Yoshida M, Shimizu M, Nakamura T. Lack of increase in postoperative complications with low-dose methotrexate therapy in patients with rheumatoid arthritis undergoing elective orthopedic surgery. Mod Rheumatol. 2006;16(1):14-9.

18. Escalante A, Beardmore TD. Risk factors for early wound complications after orthopedic surgery for rheumatoid arthritis. J Rheumatol. 1995;22(10):1844-51.

19. Bibbo C, Anderson RB, Davis WH, Norton J. The influence of rheumatoid chemotherapy, age, and presence of rheumatoid nodules on postoperative complications in rheumatoid foot and ankle surgery: analysis of 725 procedures in 104 patients [corrected]. Foot Ankle Int. 2003;24(1):40-4.
20. Muniz LF, Pereira RM, Silva TF, Bonfa E, Borba EF. Impact of therapy on metabolic syndrome in young adult premenopausal female lupus patients: beneficial effect of antimalarials. Arthritis Care Res (Hoboken). 2015;67(9):1255-62.

21. Fasano S, Margiotta DP, Navarini L, Pierro L, Pantano I, Riccardi A, et al. Primary prevention of cardiovascular disease in patients with systemic lupus erythematosus: case series and literature review. Lupus. 2017;26:1463-72.

22. Fasano S, Pierro L, Pantano I, Iudici M, Valentini G. Longterm hydroxychloroquine therapy and lowdose aspirin may have an additive effectiveness in the primary prevention of cardiovascular events in patients with systemic lupus erythematosus. J Rheumatol. 2017;44(7):1032-8.

23. Jenks KA, Stamp LK, O’Donnell JL, Savage RL, Chapman PT. Leflunomide-associated infections in rheumatoid arthritis. J Rheumatol. 2007;34(11):2201-3.

24. Strand V, Cohen S, Schiff M, Weaver A, Fleischmann R, Cannon G, et al. Treatment of active rheumatoid arthritis with leflunomide compared with placebo and methotrexate. Leflunomide Rheumatoid Arthritis Investigators Group. Arch Intern Med. 1999;159(21):2542-50.

25. Smolen JS, Kalden JR, Scott DL, Rozman B, Kvien TK, Larsen A, et al. Efficacy and safety of leflunomide compared with placebo and sulphasalazine in active rheumatoid arthritis: a double-blind, randomised, multicentre trial. European Leflunomide Study Group. Lancet. 1999;353(9149):259-66.

26. Fuerst M, Mohl H, Baumgartel K, Ruther W. Leflunomide increases the risk of early healing complications in patients with rheumatoid arthritis undergoing elective orthopedic surgery. Rheumatol Int. 2006;26(12):1138-42.

27. Tanaka N, Sakahashi H, Sato E, Hirose K, Ishima T, Ishii S. Examination of the risk of continuous leflunomide treatment on the incidence of infectious complications after joint arthroplasty in patients with rheumatoid arthritis. J Clin Rheumatol. $2003 ; 9(2): 115-8$.

28. Sindhu K, Cohen B, Gil JA. Perioperative management of rheumatoid medications in orthopedic surgery. Orthopedics. 2017;40(5):282-6.

29. Muller M, Pippi-Ludwig W. [Perioperative management of patients with rheumatoid arthritis]. Anaesthesist. 2014;63(11):883-94 (quiz 95-6).

30. Das KM, Dubin R. Clinical pharmacokinetics of sulphasalazine. Clin Pharmacokinet. 
31. Strand V, Scott DL, Emery P, Kalden JR, Smolen JS, Cannon GW, et al. Physical function and health related quality of life: analysis of 2-year data from randomized, controlled studies of leflunomide, sulfasalazine, or methotrexate in patients with active rheumatoid arthritis. J Rheumatol. 2005;32(4):590-601.

32. den Broeder AA, Creemers MC, Fransen J, de Jong E, de Rooij DJ, Wymenga A, et al. Risk factors for surgical site infections and other complications in elective surgery in patients with rheumatoid arthritis with special attention for anti-tumor necrosis factor: a large retrospective study. J Rheumatol. 2007;34(4):689-95.

33. Pieringer H, Stuby U, Biesenbach G. Patients with rheumatoid arthritis undergoing surgery: how should we deal with antirheumatic treatment? Semin Arthritis Rheum. 2007;36(5):278-86.

34. Strand V, Singh JA. Improved health-related quality of life with effective disease-modifying antirheumatic drugs: evidence from randomized controlled trials. Am J Manag Care. 2008;14(4):234-54.

35. Kremer JM, Bloom BJ, Breedveld FC, Coombs JH, Fletcher MP, Gruben D, et al. The safety and efficacy of a JAK inhibitor in patients with active rheumatoid arthritis: results of a double-blind, placebocontrolled phase IIa trial of three dosage levels of CP-690,550 versus placebo. Arthritis Rheum. 2009;60(7):1895-905.

36. Dowty ME, Lin J, Ryder TF, Wang W, Walker GS, Vaz A, et al. The pharmacokinetics, metabolism, and clearance mechanisms of tofacitinib, a janus kinase inhibitor, in humans. Drug Metab Dispos. 2014;42(4):759-73.

37. Palmisano AC, Kuhn AW, Urquhart AG, Pour AE. Post-operative medical and surgical complications after primary total joint arthroplasty in solid organ transplant recipients: a case series. Int Orthop. 2017;41(1):13-9.

38. Klement MR, Penrose CT, Bala A, Wellman SS, Bolognesi MP, Seyler TM. How Do previous solid organ transplant recipients fare after primary total knee arthroplasty? J Arthroplast. 2016;31(3):609-615e1.

39. Fleshner PR, Michelassi F, Rubin M, Hanauer SB, Plevy SE, Targan SR. Morbidity of subtotal colectomy in patients with severe ulcerative colitis unresponsive to cyclosporin. Dis Colon Rectum. 1995;38(12):1241-5.

40. Hyde GM, Jewell DP, Kettlewell MG, Mortensen NJ. Cyclosporin for severe ulcerative colitis does not increase the rate of perioperative complications. Dis Colon Rectum. 2001;44(10):1436-40.
41. Yiu ZZ, Warren RB. Novel oral therapies for psoriasis and psoriatic arthritis. Am J Clin Dermatol. 2016;17(3):191-200.

42. Kavanaugh A, Mease PJ, Gomez-Reino JJ, Adebajo AO, Wollenhaupt J, Gladman DD, et al. Treatment of psoriatic arthritis in a phase 3 randomised, placebo-controlled trial with apremilast, an oral phosphodiesterase 4 inhibitor. Ann Rheum Dis. 2014;73(6):1020-6.

43. George MD, Baker JF, Hsu JY, Wu Q, Xie F, Chen L, et al. Perioperative timing of infliximab and the risk of serious infection after elective hip and knee arthroplasty. Arthritis Care Res (Hoboken). 2017;69(12):1845-54.

44. Furie R, Petri M, Zamani O, Cervera R, Wallace DJ, Tegzova D, et al. A phase III, randomized, placebocontrolled study of belimumab, a monoclonal antibody that inhibits B lymphocyte stimulator, in patients with systemic lupus erythematosus. Arthritis Rheum. 2011;63(12):3918-30.

45. Navarra SV, Guzman RM, Gallacher AE, Hall S, Levy RA, Jimenez RE, et al. Efficacy and safety of belimumab in patients with active systemic lupus erythematosus: a randomised, placebo-controlled, phase 3 trial. Lancet. 2011;377(9767):721-31.

46. Murray E, Perry M. Off-label use of rituximab in systemic lupus erythematosus: a systematic review. Clin Rheumatol. 2010;29(7):707-16.

47. Ginzler EM, Wallace DJ, Merrill JT, Furie RA, Stohl W, Chatham WW, et al. Disease control and safety of belimumab plus standard therapy over 7 years in patients with systemic lupus erythematosus. J Rheumatol. 2014;41(2):300-9.

48. Colebatch AN, Marks JL, Edwards CJ. Safety of nonsteroidal anti-inflammatory drugs, including aspirin and paracetamol (acetaminophen) in people receiving methotrexate for inflammatory arthritis (rheumatoid arthritis, ankylosing spondylitis, psoriatic arthritis, other spondyloarthritis). Cochrane Database Syst Rev. 2011;11:CD008872.

49. Knijff-Dutmer EA, Kalsbeek-Batenburg EM, Koerts J, van de Laar MA. Platelet function is inhibited by non-selective non-steroidal anti-inflammatory drugs but not by cyclo-oxygenase-2-selective inhibitors in patients with rheumatoid arthritis. Rheumatology (Oxford). 2002;41(4):458-61.

50. Dubois RN, Abramson SB, Crofford L, Gupta RA, Simon LS, Van De Putte LB, et al. Cyclooxygenase in biology and disease. FASEB J. 1998;12(12):1063-73.

51. Wagner W, Khanna P, Furst DE. Nonsteroidal antiinflammatory drugs, disease-modifying antirheumatic drugs, nonopioid analgesics, and drugs used 
in gout. In: Katzung BG, editor. Basic \& clinical pharmacology, 9th ed. Singapore: McGraw-Hill; 2004.

52. Lee JK, Choi CH. Total knee arthroplasty in rheumatoid arthritis. Knee Surg Relat Res. 2012;24(1):1-6.

53. Mak A. Orthopedic surgery and its complication in systemic lupus erythematosus. World J Orthop. 2014;5(1):38-44.

54. Samama CM, Bastien O, Forestier F, Denninger $\mathrm{MH}$, Isetta C, Juliard JM, et al. Antiplatelet agents in the perioperative period: expert recommendations of the French Society of Anesthesiology and Intensive Care (SFAR) 2001-summary statement. Can J Anaesth. 2002;49(6):S26-35.

55. Graham DJ, Campen D, Hui R, Spence M, Cheetham C, Levy G, et al. Risk of acute myocardial infarction and sudden cardiac death in patients treated with cyclo-oxygenase 2 selective and nonselective non-steroidal anti-inflammatory drugs: nested case-control study. Lancet. 2005;365(9458):475-81.

56. Mamdani M, Juurlink DN, Lee DS, Rochon PA, Kopp A, Naglie $G$, et al. Cyclo-oxygenase-2 inhibitors versus non-selective non-steroidal anti-inflammatory drugs and congestive heart failure outcomes in elderly patients: a population-based cohort study. Lancet. 2004;363(9423):1751-6.

57. Mamdani M, Rochon P, Juurlink DN, Anderson GM, Kopp A, Naglie G, et al. Effect of selective cyclooxygenase 2 inhibitors and naproxen on shortterm risk of acute myocardial infarction in the elderly. Arch Intern Med. 2003;163(4):481-6.

58. Howe CR, Gardner GC, Kadel NJ. Perioperative medication management for the patient with rheumatoid arthritis. J Am Acad Orthop Surg. 2006;14(9):544-51.

59. Caporali R, Montecucco C. Cardiovascular effects of coxibs. Lupus. 2005;14(9):785-8.

60. Nissen SE, Yeomans ND, Solomon DH, Luscher TF, Libby P, Husni ME, et al. Cardiovascular safety of celecoxib, naproxen, or ibuprofen for arthritis. N Engl J Med. 2016;375(26):2519-29.

61. Randelli P, Randelli F, Cabitza P, Vaienti L. The effects of COX-2 anti-inflammatory drugs on soft tissue healing: a review of the literature. J Biol Regul Homeost Agents. 2010;24(2):107-14.

62. Simon AM, Manigrasso MB, O'Connor JP. Cyclooxygenase 2 function is essential for bone fracture healing. J Bone Miner Res. 2002;17(6):963-76.
63. Zhang X, Schwarz EM, Young DA, Puzas JE, Rosier $\mathrm{RN}$, O'Keefe RJ. Cyclooxygenase- 2 regulates mesenchymal cell differentiation into the osteoblast lineage and is critically involved in bone repair. J Clin Invest. 2002;109(11):1405-15.

64. Chikazu D, Tomizuka K, Ogasawara T, Saijo H, Koizumi T, Mori Y, et al. Cyclooxygenase- 2 activity is essential for the osseointegration of dental implants. Int $\mathrm{J}$ Oral Maxillofac Surg. 2007;36(5):441-6.

65. Dvivedi S, Tiwari SM, Sharma A. Effect of ibuprofen and diclofenac sodium on experimental would healing. Indian J Exp Biol. 1997;35(11):1243-5.

66. Teerawattananon C, Tantayakom P, Suwanawiboon B, Katchamart W. Risk of perioperative bleeding related to highly selective cyclooxygenase- 2 inhibitors: a systematic review and meta-analysis. Semin Arthritis Rheum. 2017;46(4):520-8.

67. Mochizuki T, Yano K, Ikari K, Hiroshima R, Takaoka $\mathrm{H}$, Kawakami K, et al. Tramadol hydrochloride/acetaminophen combination versus non-steroidal anti-inflammatory drug for the treatment of perioperative pain after total knee arthroplasty: a prospective, randomized, open-label clinical trial. J Orthop Sci. 2016;21(5):625-9.

68. Kirwan JR, Hickey SH, Hallgren R, Mielants H, Bjorck E, Persson T, et al. The effect of therapeutic glucocorticoids on the adrenal response in a randomized controlled trial in patients with rheumatoid arthritis. Arthritis Rheum. 2006;54(5):1415-21.

69. Somayaji R, Barnabe C, Martin L. Risk factors for infection following total joint arthroplasty in rheumatoid arthritis. Open Rheumatol J. 2013;7:119-24.

70. Marik PE, Varon J. Requirement of perioperative stress doses of corticosteroids: a systematic review of the literature. Arch Surg. 2008;143(12):1222-6.

71. Salem M, Tainsh RE Jr, Bromberg J, Loriaux DL, Chernow B. Perioperative glucocorticoid coverage. A reassessment 42 years after emergence of a problem. Ann Surg. 1994;219(4):416-25.

72. Gilson M, Gossec L, Mariette X, Gherissi D, Guyot $\mathrm{MH}$, Berthelot JM, et al. Risk factors for total joint arthroplasty infection in patients receiving tumor necrosis factor alpha-blockers: a case-control study. Arthritis Res Ther. 2010;12(4):R145.

73. Kawakami K, Ikari K, Kawamura K, Tsukahara S, Iwamoto $\mathrm{T}$, Yano $\mathrm{K}$, et al. Complications and features after joint surgery in rheumatoid arthritis patients treated with tumour necrosis factor-alpha blockers: perioperative interruption of tumour 
necrosis factor-alpha blockers decreases complications? Rheumatology (Oxf). 2010;49(2):341-7.

74. Lin JA, Liao CC, Lee YJ, Wu CH, Huang WQ, Chen TL. Adverse outcomes after major surgery in patients with systemic lupus erythematosus: a nationwide population-based study. Ann Rheum Dis. $2014 ; 73(9): 1646-51$

75. Luessenhop CP, Higgins LD, Brause BD, Ranawat CS. Multiple prosthetic infections after total joint arthroplasty. Risk factor analysis. J Arthroplasty. 1996;11(7):862-8.

76. Kehlet $\mathrm{H}$, Binder C. Value of an ACTH test in assessing hypothalamic-pituitary-adrenocortical function in glucocorticoid-treated patients. BMJ. 1973;2(5859):147-9.

77. Fein AW, Figgie CA, Dodds TR, Wright-Chisem J, Parks ML, Mandl LA, et al. Systemic lupus erythematosus does not increase risk of adverse events in the first 6 months after total knee arthroplasty. J Clin Rheumatol. 2016;22(7):355-9.

78. Glowniak JV, Loriaux DL. A double-blind study of perioperative steroid requirements in secondary adrenal insufficiency. Surgery. 1997;121(2):123-9.

79. Leopold SS, Casnellie MT, Warme WJ, Dougherty PJ, Wingo ST, Shott S. Endogenous cortisol production in response to knee arthroscopy and total knee arthroplasty. J Bone Jt Surg Am. 2003;85(A(11)):2163-7.

80. Danoff JR, Moss G, Liabaud B, Geller JA. Total knee arthroplasty considerations in rheumatoid arthritis. Autoimmun Dis. 2013;2013:185340.

81. Randelli P, Evola FR, Cabitza P, Polli L, Denti M, Vaienti L. Prophylactic use of antibiotic-loaded bone cement in primary total knee replacement. Knee Surg Sports Traumatol Arthrosc. 2010;18(2):181-6.

82. Bratzler DW, Dellinger EP, Olsen KM, Perl TM, Auwaerter PG, Bolon MK, et al. Clinical practice guidelines for antimicrobial prophylaxis in surgery. Am J Health Syst Pharm. 2013;70(3):195-283.

83. Bode LG, Kluytmans JA, Wertheim HF, Bogaers D, Vandenbroucke-Grauls CM, Roosendaal R, et al. Preventing surgical-site infections in nasal carriers of Staphylococcus aureus. N Engl J Med. 2010;362(1):9-17.

84. Jernigan JA, Pullen AL, Flowers L, Bell M, Jarvis WR. Prevalence of and risk factors for colonization with methicillin-resistant Staphylococcus aureus at the time of hospital admission. Infect Control Hosp Epidemiol. 2003;24(6):409-14.
85. Thornley P, Evaniew N, Riediger M, Winemaker M, Bhandari M, Ghert M. Postoperative antibiotic prophylaxis in total hip and knee arthroplasty: a systematic review and meta-analysis of randomized controlled trials. CMAJ Open. 2015;3(3):E338-43.

86. Bartels CM, Buhr KA, Goldberg JW, Bell CL, Visekruna $M$, Nekkanti $S$, et al. Mortality and cardiovascular burden of systemic lupus erythematosus in a US population-based cohort. J Rheumatol. 2014;41(4):680-7.

87. Agca R, Heslinga SC, Rollefstad S, Heslinga M, McInnes IB, Peters MJ, et al. EULAR recommendations for cardiovascular disease risk management in patients with rheumatoid arthritis and other forms of inflammatory joint disorders: 2015/2016 update. Ann Rheum Dis. 2017;76(1):17-28.

88. Bremander A, Petersson IF, Bergman S, Englund M. Population-based estimates of common comorbidities and cardiovascular disease in ankylosing spondylitis. Arthritis Care Res (Hoboken). 2011;63(4):550-6.

89. Urban MK, Jules-Elysee K, Loughlin C, Kelsey W, Flynn E. The one year incidence of postoperative myocardial infarction in an orthopedic population. HSS J. 2008;4(1):76-80.

90. Lee TH, Marcantonio ER, Mangione CM, Thomas EJ, Polanczyk CA, Cook EF, et al. Derivation and prospective validation of a simple index for prediction of cardiac risk of major noncardiac surgery. Circulation. 1999;100(10):1043-9.

91. Yazdanyar A, Wasko MC, Scalzi LV, Kraemer KL, Ward MM. Short-term perioperative all-cause mortality and cardiovascular events in women with systemic lupus erythematosus. Arthritis Care Res (Hoboken). 2013;65(6):986-91.

92. Domsic RT, Lingala B, Krishnan E. Systemic lupus erythematosus, rheumatoid arthritis, and postarthroplasty mortality: a cross-sectional analysis from the nationwide inpatient sample. J Rheumatol. 2010;37(7):1467-72.

93. Fleisher LA, Fleischmann KE, Auerbach AD, Barnason SA, Beckman JA, Bozkurt B, et al. 2014 ACC/ AHA guideline on perioperative cardiovascular evaluation and management of patients undergoing noncardiac surgery: a report of the American College of Cardiology/American Heart Association Task Force on Practice Guidelines. Circulation. 2014;130(24):e278-333.

94. Gupta PK, Gupta H, Sundaram A, Kaushik M, Fang $\mathrm{X}$, Miller WJ, et al. Development and validation of a risk calculator for prediction of cardiac risk after surgery. Circulation. 2011;124(4):381-7. 
95. Goodman SM, Mackenzie CR. Cardiovascular risk in the rheumatic disease patient undergoing orthopedic surgery. Curr Rheumatol Rep. 2013;15(9):354.

96. Schror K. Aspirin and platelets: the antiplatelet action of aspirin and its role in thrombosis treatment and prophylaxis. Semin Thromb Hemost. 1997;23(4):349-56.

97. Smilowitz NR, Oberweis BS, Nukala S, Rosenberg A, Stuchin S, Iorio R, et al. Perioperative antiplatelet therapy and cardiovascular outcomes in patients undergoing joint and spine surgery. J Clin Anesth. 2016;35:163-9.

98. Oscarsson A, Gupta A, Fredrikson M, Jarhult J, Nystrom M, Pettersson E, et al. To continue or discontinue aspirin in the perioperative period: a randomized, controlled clinical trial. $\mathrm{Br} \mathrm{J}$ Anaesth. 2010;104(3):305-12.

99. Mollmann H, Nef HM, Hamm CW. Clinical pharmacology: antiplatelet therapy during surgery. Heart. 2010;96(12):986-91.

100. Gerstein NS, Carey MC, Cigarroa JE, Schulman PM. Perioperative aspirin management after POISE-2: some answers, but questions remain. Anesth Analg. 2015;120(3):570-5.

101. Douketis JD, Spyropoulos AC, Spencer FA, Mayr M, Jaffer AK, Eckman MH, et al. Perioperative management of antithrombotic therapy: antithrombotic therapy and prevention of thrombosis, 9th ed: American College of Chest Physicians evidencebased clinical practice guidelines. Chest. 2012;141(2 Suppl):e326S-50S.

102. Ramagopalan SV, Wotton CJ, Handel AE, Yeates D, Goldacre MJ. Risk of venous thromboembolism in people admitted to hospital with selected immunemediated diseases: record-linkage study. BMC Med. 2011;9:1.

103. Lee JJ, Pope JE. A meta-analysis of the risk of venous thromboembolism in inflammatory rheumatic diseases. Arthritis Res Ther. 2014;16(5):435.

104. Yusuf HR, Hooper WC, Grosse SD, Parker CS, Boulet SL, Ortel TL. Risk of venous thromboembolism occurrence among adults with selected autoimmune diseases: a study among a U.S. cohort of commercial insurance enrollees. Thromb Res. 2015;135(1):50-7.

105. Kaplan MJ, Salmon JE. How does interferon-alpha insult the vasculature? Let me count the ways. Arthritis Rheum. 2011;63(2):334-6.

106. Dessein PH, Solomon A, Woodiwiss AJ, Norton GR, Tsang L, Gonzalez-Gay MA. Marked independent relationship between circulating interleukin-6 concentrations and endothelial activation in rheumatoid arthritis. Mediat Inflamm. 2013;2013:510243.

107. Wakefield TW, Myers DD, Henke PK. Mechanisms of venous thrombosis and resolution. Arterioscler Thromb Vasc Biol. 2008;28(3):387-91.

108. Zoller B, Li X, Sundquist J, Sundquist K. Autoimmune diseases and venous thromboembolism: a review of the literature. Am J Cardiovasc Dis. 2012;2(3):171-83.

109. Deitelzweig SB, Lin J, Lin G. Preventing venous thromboembolism following orthopedic surgery in the United States: impact of special populations on clinical outcomes. Clin Appl Thromb Hemost. 2011;17(6):640-50.

110. Perka C. Preoperative versus postoperative initiation of thromboprophylaxis following major orthopedic surgery: safety and efficacy of postoperative administration supported by recent trials of new oral anticoagulants. Thromb J. 2011;9:17.

111. Geerts WH, Bergqvist D, Pineo GF, Heit JA, Samama CM, Lassen MR, et al. Prevention of venous thromboembolism: American College of Chest Physicians evidence-based clinical practice guidelines (8th edition). Chest. 2008;133(6 Suppl):381S-453S.

112. Dahl OE, Caprini JA, Colwell CW Jr, Frostick SP, Haas S, Hull RD, et al. Fatal vascular outcomes following major orthopedic surgery. Thromb Haemost. 2005;93(5):860-6.

113. Drenkard C, Villa AR, Alarcon-Segovia D, PerezVazquez ME. Influence of the antiphospholipid syndrome in the survival of patients with systemic lupus erythematosus. J Rheumatol. 1994;21(6):1067-72.

114. Miyakis S, Lockshin MD, Atsumi T, Branch DW, Brey RL, Cervera R, et al. International consensus statement on an update of the classification criteria for definite antiphospholipid syndrome (APS). J Thromb Haemost. 2006;4(2):295-306.

115. Berkun Y, Elami A, Meir K, Mevorach D, Naparstek Y. Increased morbidity and mortality in patients with antiphospholipid syndrome undergoing valve replacement surgery. J Thorac Cardiovasc Surg. 2004;127(2):414-20.

116. Merrill JT, Asherson RA. Catastrophic antiphospholipid syndrome. Nat Clin Pract Rheumatol. 2006;2(2):81-9.

117. Erkan D, Leibowitz E, Berman J, Lockshin MD. Perioperative medical management of antiphospholipid syndrome: hospital for special surgery 
experience, review of literature, and recommendations. J Rheumatol. 2002;29(4):843-9.

118. Legault KJ, Ugarte A, Crowther MA, Ruiz-Irastorza G. Prevention of recurrent thrombosis in antiphospholipid syndrome: different from the general population? Curr Rheumatol Rep. 2016;18(5):26.

119. de Groot PG, Lutters B, Derksen RH, Lisman T, Meijers JC, Rosendaal FR. Lupus anticoagulants and the risk of a first episode of deep venous thrombosis. J Thromb Haemost. 2005;3(9):1993-7.

120. Ruffatti A, Del Ross T, Ciprian M, Nuzzo M, Rampudda M, Bertero MT, et al. Risk factors for a first thrombotic event in antiphospholipid antibody carriers. A multicentre, retrospective follow-up study. Ann Rheum Dis. 2009;68(3):397-9.

121. Raso S, Sciascia S, Kuzenko A, Castagno I, Marozio L, Bertero MT. Bridging therapy in antiphospholipid syndrome and antiphospholipid antibodies carriers: case series and review of the literature. Autoimmun Rev. 2015;14(1):36-42.

122. Atisha-Fregoso Y, Espejo-Poox E, Carrillo-Maravilla E, Pulido-Ramirez AL, Lugo Baruqui D, HernandezMolina G, et al. Perioperative management of patients with antiphospholipid syndrome: a single-center experience. Rheumatol Int. 2017;37(7):1159-64.

123. Bala MM, Celinska-Lowenhoff M, Szot W, Padjas A, Kaczmarczyk M, Swierz MJ, et al. Antiplatelet and anticoagulant agents for secondary prevention of stroke and other thromboembolic events in people with antiphospholipid syndrome. Cochrane Database Syst Rev. 2017;10:CD012169.

124. Ruiz-Irastorza G, Egurbide MV, Pijoan JI, Garmendia M, Villar I, Martinez-Berriotxoa A, et al. Effect of antimalarials on thrombosis and survival in patients with systemic lupus erythematosus. Lupus. 2006;15(9):577-83.

125. Tektonidou MG, Laskari K, Panagiotakos DB, Moutsopoulos HM. Risk factors for thrombosis and primary thrombosis prevention in patients with systemic lupus erythematosus with or without antiphospholipid antibodies. Arthritis Rheum. 2009;61(1):29-36.

126. Becker-Merok A, Nossent J. Prevalence, predictors and outcome of vascular damage in systemic lupus erythematosus. Lupus. 2009;18(6):508-15.

127. Carter AE, Eban R. Prevention of postoperative deep venous thrombosis in legs by orally administered hydroxychloroquine sulphate. BMJ. 1974;3(5923):94-5.

128. Wu TK, Tsapogas MJ, Jordan FR. Prophylaxis of deep venous thrombosis by hydroxychloroquine sulfate and heparin. Surg Gynecol Obstet. 1977; 145(5):714-8.

129. Snook GA, Chrisman OD, Wilson TC. Thromboembolism after surgical treatment of hip fractures. Clin Orthop Relat Res. 1981;155:21-4.

130. Cooke ED, Dawson MH, Ibbotson RM, Bowcock SA, Ainsworth ME, Pilcher MF. Failure of orally administered hydroxychloroquine sulphate to prevent venous thromboembolism following elective hip operations. J Bone Jt Surg Am. 1977; 59(4):496-500.

131. Loudon JR. Hydroxychloroquine and postoperative thromboembolism after total hip replacement. Am J Med. 1988;85(4A):57-61.

132. Petri M. Use of hydroxychloroquine to prevent thrombosis in systemic lupus erythematosus and in antiphospholipid antibody-positive patients. Curr Rheumatol Rep. 2011;13(1):77-80.

133. Erkan D, Bateman H, Lockshin MD. Lupus anticoagulant-hypoprothrombinemia syndrome associated with systemic lupus erythematosus: report of 2 cases and review of literature. Lupus. 1999;8(7): $560-4$.

134. Cugno M, Gualtierotti R, Tedeschi A, Meroni PL. Autoantibodies to coagulation factors: from pathophysiology to diagnosis and therapy. Autoimmun Rev. 2014;13(1):40-8.

135. Asherson RA, Cervera R, de Groot PG, Erkan D, Boffa MC, Piette JC, et al. Catastrophic antiphospholipid syndrome: international consensus statement on classification criteria and treatment guidelines. Lupus. 2003;12(7):530-4.

136. Cervera R, Rodriguez-Pinto I, Colafrancesco S, Conti F, Valesini G, Rosario C, et al. 14th International congress on antiphospholipid antibodies task force report on catastrophic antiphospholipid syndrome. Autoimmun Rev. 2014;13(7):699-707.

137. Ortel TL, Erkan D, Kitchens CS. How I treat catastrophic thrombotic syndromes. Blood. 2015;126(11):1285-93.

138. Berman H, Rodriguez-Pinto I, Cervera R, Morel N, Costedoat-Chalumeau N, Erkan D, et al. Rituximab use in the catastrophic antiphospholipid syndrome: descriptive analysis of the CAPS registry patients receiving rituximab. Autoimmun Rev. 2013;12(11): 1085-90.

139. Kronbichler A, Frank R, Kirschfink M, Szilagyi A, Csuka D, Prohaszka Z, et al. Efficacy of eculizumab in a patient with immunoadsorption-dependent catastrophic antiphospholipid syndrome: a case report. Medicine (Baltim). 2014;93(26):e143. 